\title{
The difference between epistemic and metaphysical necessity
}

\author{
Martin Glazier ${ }^{1}$
}

Received: 25 May 2017 / Accepted: 13 November 2017

(C) Springer Science+Business Media B.V., part of Springer Nature 2017

\begin{abstract}
Philosophers have observed that metaphysical necessity appears to be a true or real or genuine form of necessity while epistemic necessity does not. Similarly, natural necessity appears genuine while deontic necessity does not. But what is it for a form of necessity to be genuine? I defend an account of genuine necessity in explanatory terms. The genuine forms of necessity, I argue, are those that provide what I call necessitarian explanation. I discuss the relationship of necessitarian explanation to ground.
\end{abstract}

Keywords Necessity · Genuine · Explanation · Ground · Open future

\section{Introduction}

There is a familiar distinction between epistemic and metaphysical senses of necessity. In one sense it is not possible that Jones is the burglar, for she is known to have been abroad at the time of the break-in. Yet in another sense this is possible, for she had the motive and the means. It is therefore epistemically necessary, but not metaphysically necessary, that Jones is innocent. A proposition may also be metaphysically necessary but not epistemically necessary: that water is $\mathrm{H}_{2} \mathrm{O}$, for instance, once had this status.

These two forms of necessity differ in a number of ways. But perhaps the most striking difference is that metaphysical necessity appears to be a true or real or genuine form of necessity while epistemic necessity does not. Kment (2006, p. 258) captures this aspect of metaphysical necessity well: 'If a certain proposition is metaphysically

\footnotetext{
$凶 \quad$ Martin Glazier glazier@nyu.edu

1 Postdoctoral Fellow, Instituto de Investigaciones Filosóficas, UNAM, Circuito Mario de la Cueva, Ciudad Universitaria, 04510 Coyoacán, Ciudad de México, Mexico
} 
impossible,' he writes, 'then this is so because that there is some particularly formidable obstacle that prevents the proposition from being true.' It seems somehow wrong to say the same of a proposition that is epistemically impossible. But what does this difference come to? What is it, in other words, for a form of necessity to be genuine?

This difference between epistemic and metaphysical necessity has been observed by many philosophers. Thus Kripke (1980, p. 142) contrasts epistemic modality with 'genuine de re modalities', by which he means to include metaphysical modality. Fine (2002, p. 255) takes metaphysical necessity, but not epistemic necessity, to be a genuine form of necessity. Soames (2011, p. 172) says that 'before we know much about what is actual, there are many epistemically possible world-states that appear to be genuinely possible, and so remain candidates for being metaphysically possible'. Murray and Wilson (2012, p. 213) contrast 'merely epistemic' necessity with 'properly genuine' metaphysical necessity. And Wilson (2013, p. 657) takes metaphysical possibilities to be 'genuine possibilities' that 'really could happen' in contrast with 'merely epistemic possibilities'. 1

These philosophers, however, have said little about how to understand the notion of genuineness. And yet we may suspect that further elucidation should be possible. After all, metaphysical necessity is not the only genuine form of necessity. There is, for instance, natural necessity, the necessity attaching to what is required by the laws of nature. Nor is epistemic necessity the only nongenuine form of necessity. There is, for instance, deontic necessity, the necessity attaching to what is morally required. What is this quality of genuineness had by the first pair but not the second?

I will argue that genuineness should be understood in explanatory terms. The genuine forms of necessity are those that provide what I call necessitarian explanation. Nongenuine forms of necessity, by contrast, do not in general provide such explanation.

Although I will propose an account of what it is, in general, for a form of necessity to be genuine, I will have much less to say about how to understand the particular forms of necessity themselves. The notion of metaphysical necessity, for instance, has been familiar since Kripke, yet there has been no shortage of controversy over how it is to be understood. I have nothing to add to this discussion and will simply assume that we have a grasp of the notion. It has sometimes been suggested (e.g. by Rosen 2006) that there might be several notions of metaphysical necessity. Those who hold this view may take me to be speaking about all such notions.

Whether there are several notions of metaphysical necessity is controversial; not so for epistemic necessity. A proposition is epistemically necessary in one sense if it is required by what is known. Thus since Jones is known to have been abroad at the time of the break-in, it is epistemically necessary that she is innocent. But there are other notions of epistemic necessity as well. For instance, we may say that a proposition is epistemically necessary in the sense that it is required by the evidence, or in the sense that it is a priori. Although in what follows I will focus on epistemic necessity in the

\footnotetext{
1 Some philosophers have preferred to say that epistemic and metaphysical necessity differ in their reality (Edgington 2004, p. 2) or objectivity (Williamson 2016) rather than their genuineness.
} 
sense of what is required by what is known, my account of the difference between epistemic and metaphysical necessity will apply to the other notions as well. ${ }^{2}$

\section{What genuineness is not}

Let us now take up our central question. What is it for a form of necessity to be genuine?

An immediate suggestion is that a form of necessity is genuine just in case it is logically sufficient for truth, or is 'factive'. This suggestion correctly counts metaphysical necessity as genuine, since every metaphysically necessary proposition is true. But the suggestion also wrongly counts epistemic necessity as genuine. For since what is known must be true, so must what is required by what is known. And so every epistemically necessary proposition is true.

Might we instead understand genuineness as mind-independence? After all, metaphysical necessity might be thought to be mind-independent in a way that epistemic necessity is not. Of course, the notion of mind-independence is less than perfectly clear. But however precisely we understand the notion it is inadequate as an account of genuineness.

To see this, consider deontic necessity, the necessity attaching to what is morally required. This is the sense in which it might be thought that one must keep one's promises. This form of necessity seems no more genuine than epistemic necessity. In Kmentian terms, no obstacle prevents promise-breaking, as those of us who have broken one know all too well. But deontic necessity might well be thought to be mindindependent in just the way that metaphysical necessity is. For instance, it might be thought a mind-independent matter that there must be no torture in the world. But even if this is so, it hardly makes deontic necessity genuine. ${ }^{3}$

Perhaps it is instead a lack of relativity that makes for genuineness. After all, what is epistemically necessary is relative in a way that what is metaphysically necessary is not. Relative to me, perhaps, it is a known proposition that water is $\mathrm{H}_{2} \mathrm{O}$, while relative to Aristotle it is not, and so relative to me this proposition is epistemically necessary, while

\footnotetext{
2 Many philosophers hold that every a priori proposition is metaphysically necessary. Since metaphysical necessity is genuine, must these philosophers take epistemic necessity, in the sense of a priority, to be genuine as well? No. A form of necessity may fail to be genuine even if every proposition with that form of necessity also possesses a distinct form of necessity that is genuine. The account developed below explains how such a situation is possible.

3 Might we instead take a form of necessity to be genuine just in case it is both mind-independent and sufficient for truth? Since deontic necessity is not sufficient for truth, this proposal correctly counts it as nongenuine. But the proposal mishandles the historical form of necessity (discussed further below). A fourdimensionalist in the mold of Sider (2001), for instance, might understand the claim that a given proposition $p$ is historically necessary as nothing more than the claim that $p$ follows, in a certain sense, from the true propositions about our own time and the times that precede it (cf. Lewis 1986, p. 7). Historical necessity, on this view, will be both mind-independent and sufficient for truth. Yet the four-dimensionalist sees time as akin to space and will no more admit a genuine form of necessity connected to times earlier than our own than she will admit one connected to points of space to her left.
} 
relative to Aristotle it is not. ${ }^{4}$ By contrast, one cannot sensibly say that this proposition is metaphysically necessary relative to one person but not relative to another. In this sense, metaphysical necessity is not a relative matter. One might therefore take a form of necessity to be genuine just in case, in this sense, it is nonrelative.

But deontic necessity might well be thought nonrelative in just the way that metaphysical necessity is. It might be thought, for instance, that one cannot sensibly say that it is the case relative to me, but not to you, that there must be no torture in the world. Put another way, it might be thought not to be a relative matter that morality prohibits torture. Yet that would not make deontic necessity genuine. ${ }^{5}$

One might think instead to understand genuineness in logical terms. A form of necessity might be taken to be genuine just in case it admits not only de dicto but also de re necessities. (Perhaps it is this account that Kripke has in mind when he speaks of 'genuine de re modalities'.) The account does seem to correctly classify metaphysical necessity as genuine, for there are de re as well as de dicto metaphysical necessities. But it fails to correctly classify epistemic necessity. There are of course de dicto epistemic necessities: it is known (and so is epistemically necessary) that there are eight planets. But there are also de re epistemic necessities: it is known of Earth that it is round, and so we may say of Earth that it is epistemically necessary that it is round (cf. Chalmers 2011, pp. 87-88). Yet epistemic necessity is not genuine.

Might genuineness instead be a matter of obeying the $\mathrm{K}$ axiom $((\square A \wedge \square(A \rightarrow B))$ $\rightarrow \square B)$ ? In support of such an account, it might be claimed that it at least correctly classifies metaphysical and epistemic necessity. After all, the former surely obeys the axiom. And as for the latter, several philosophers have observed that what is known might not be closed under modus ponens. That is, $A$ and $A \rightarrow B$ might be known without $B$ 's being known, perhaps because the derivation of $B$ has not been carried out (Hacking 1967; Teller 1972; DeRose 1991).

However, to be epistemically necessary in our sense is not to be known but to be required by what is known. And one may plausibly take what is required by what is known to be closed under modus ponens. That is, one may plausibly think that if $A$ and $A \rightarrow B$ are required by what is known, then $B$ will also be required by what is known. Epistemic necessity will then obey the $\mathrm{K}$ axiom just as metaphysical necessity does. Yet this would hardly make it genuine.

Perhaps, then, for an account of genuineness we should look not to logic but to metaphysics. In the contemporary metaphysical context, a particularly salient thought

\footnotetext{
4 Epistemic necessity need not be taken to be relative to a person. It might instead be taken to be relative to something else, such as a group or body of knowledge. See the papers in Egan and Weatherson (2011) for discussion.

5 Again one might think to accommodate the deontic case by taking a form of necessity to be genuine just in case it is both nonrelative and sufficient for truth. But one might agree with Quine (1943, p. 121) that "among the various possible senses of the vague adverb "necessarily", we can single out one-the sense of analytic necessity - according to the following criterion: the result of applying "necessarily" to a statement is true if, and only if, the original statement is analytic.' And one might have a purely epistemic conception of analyticity on which a statement is analytic just in case 'grasp of its meaning alone suffices for justified belief in its truth' (Boghossian 1996, p. 363). Analytic necessity, so understood, is both nonrelative and sufficient for truth. Yet it is no more genuine than epistemic necessity.
} 
may be that genuineness is a matter of fundamentality. ${ }^{6}$ A form of necessity will be genuine, that is, just in case it is in some sense fundamental.

But in the first place, it seems that deontic necessity might be thought to be fundamental in whatever way metaphysical necessity is. Suppose, for example, that metaphysical necessity is fundamental in the sense that some facts about it are fundamental-perhaps, for instance, the fact that it is metaphysically necessary that a given electron is self-identical. One might take deontic necessity to be fundamental in this sense as well. After all, one might see no way to reduce the moral to the nonmoral, nor to reduce the modal to the nonmodal. One might therefore be led to take as fundamental some facts about deontic necessity — that one must treat others as ends in themselves, perhaps. But this would create no obstacle, to put it in Kmentian terms, for one who refused to treat others in this way. It would not render deontic necessity genuine.

And in the second place, one might take a genuine form of necessity to be nonfundamental as part of a general rejection of all fundamental modality. For example, one might agree with Sider (Sider 2003, p. 184) that

It is easy to get into a frame of mind according to which modal notions should not be taken as 'rock bottom', ontologically speaking. ... Whether something is a certain way seems unproblematic, but that things might be otherwise, or must be as they are, seems to call out for explanation.

But even if one rejected all fundamental modality, that would not obliterate the clear contrast between metaphysical and epistemic necessity. There would still be formidable obstacles that prevent metaphysically impossible propositions from being true, even if these obstacles are in no way fundamental. No such obstacles hinder epistemically impossible propositions.

A second metaphysically-oriented suggestion is to understand genuineness as permanence. Epistemic necessity is what one might call a temporary form of necessity: something can sensibly be said to be epistemically necessary at one time but not at another. After all, something is epistemically necessary just in case it is required by what is known, and what is known may change. Metaphysical necessity, by contrast, might be thought to be permanent. And of course there is a long tradition in Western philosophy according to which what is permanent is somehow more genuine or real or true.

One might think we can easily generate counterexamples to this account by restriction on genuine forms of necessity. Let us say, for instance, that a proposition is 'lunarly necessary' just in case it is a metaphysically necessary proposition about the moon. Thus it will be lunarly necessary that there are no round squares on the moon. Since metaphysical necessity is permanent and all lunar necessities are metaphysical necessities, lunar necessity is also permanent. But surely nothing defined in so arbitrary a way could be a genuine form of necessity.

This, however, is no counterexample to the claim that a form of necessity is genuine just in case it is permanent. For lunar 'necessity' is not really a form of necessity at

6 Accounts of fundamentality have been developed by Fine (2001), Schaffer (2009), Jenkins (2011), Sider (2011), Wilson (2014) and Raven (2016). 
all. There is no sense, for example, in which it is necessary that there are no round squares on the moon but contingent that there are no round squares on Earth.

What the failure of this objection brings out is that no proposed account of what it is for a form of necessity to be genuine, including the account developed below, will be subject to counterexample by carefully constructed definitions in the style of lunar 'necessity'. For such constructions will not be forms of necessity and so will pose no difficulty for the proposed account.

A better objection to the permanence account arises from the doctrine of the open future. The open future theorist thinks there is more than one way that events can unfold. She may hold, for instance, that it is possible both that there will be a sea battle tomorrow and that there will not be a sea battle tomorrow. The sense of possibility here is often called 'historical'. For the open future theorist, this sense of possibility is a genuine one. ${ }^{7}$ She will not be satisfied, for instance, with a multiplicity of merely epistemically possible ways for events to unfold. In A. Wilson's phrase, she holds that both the sea battle and its absence really could happen. In this sense, she thinks it is open whether there will be a sea battle tomorrow.

Corresponding to this genuine form of possibility is a genuine form of necessity. It is historically necessary, for instance, that Plato is the author of the Republic. For the open future theorist, this proposition is in a certain sense 'fixed'. Some obstacle, as it were, prevents events from unfolding in such a way that it fails to obtain.

But the open future theorist also takes the historical form of necessity to be temporary. Although on her view it is now historically necessary that Plato is the author of the Republic, it was once open whether he would write the Republic and so it was once not historically necessary that he is its author. Historical necessity, according to the doctrine of the open future, is genuine yet temporary.

The doctrine of the open future also poses a difficulty for the counterfactual account of genuineness developed by Lange $(2009, \mathrm{ch} .2) .{ }^{8}$ On this account, a form of necessity is genuine just in case the set of propositions with that form of necessity is stable in the following sense. There must be no supposition $p$ (or nested sequence of suppositions $p, q, r \ldots$ ) such that (a) $p$ is logically consistent with the set and (b) for some member $m$ of the set, had $p$ obtained, $m$ might not have obtained. But let $p$ be the supposition that Plato was a philosopher. This is logically consistent with the set of historically necessary propositions - indeed, it is a member of that set. And let $m$ be the historically necessary proposition that Plato is the author of the Republic. Since the open future theorist thinks that it was once open whether Plato would write the Republic, she will think that it was possible for him not to do so-presumably, even well into his philosophical career. For her, then, even if Plato had (still) been a philosopher, he might not have been the author of the Republic. In other words, had $p$ obtained, $m$ might not have obtained. The set of historically necessary propositions thus fails to be

\footnotetext{
7 Thus Barnes and Cameron (2011, p. 2) take the open future theorist to hold that 'there are multiple genuinely possible ways our history could go'.

8 Although Lange himself does not think historical necessity is genuine (p. 211), I take it that any reasonable account of genuineness should at least be compatible with the doctrine of the open future.
} 
stable and so Lange's account will classify this form of necessity as nongenuine. Yet according to the doctrine of the open future it is genuine. ${ }^{9}$

How then should the notion of genuineness be understood? What, in a word, is the difference between epistemic and metaphysical necessity?

I would like to suggest that we were too quick in dismissing the thought that a genuine form of necessity is one that is sufficient for truth. Of course, some nongenuine forms of necessity, such as epistemic necessity, are logically sufficient for truth. But this shows only that the notion of sufficiency cannot be a purely logical one. It leaves open the possibility of some richer notion of sufficiency in terms of which genuineness might be understood. I believe the required notion of sufficiency is an explanatory one. But what is this explanatory notion of sufficiency?

\section{Necessitarian explanation}

Philosophers have observed that some necessary propositions admit of a distinctive form of explanation. Lange (2009, p. 6) offers a nice example:

That it is impossible to divide 23 evenly by 3 explains why no one has ever succeeded in figuring out a way to do so, no matter how much mathematics she knows - and why every time someone tries to divide 23 objects evenly into thirds, she fails. None of these efforts could have succeeded. They all fail because they must; their failure was inevitable.

Put another way, there are no trisections of 23 objects because there cannot be. Such events are impossible.

The explanandum of an explanation of this form need not be a generalization. Why did Anaxagoras fail in his attempt to square the circle? Because it is not possible that he should have succeeded. Nor need the explanandum involve an agent. Why are there no gold atoms with one hundred protons? Because it is not possible that any gold atom should have one hundred protons. Nor, finally, need the explanandum be a 'negative' fact. Why is the property being a property instantiated? Because it must be, if only through instantiating itself. Let us call explanations of this form necessitarian explanations.

In each of these cases of necessitarian explanation it is clear what the explanandum is. But what is the explanans? When we give a necessitarian explanation of the proposition that $A$, do we appeal to the necessity of $A$ or do we rather appeal to the impossibility of $\neg A$ ? Although nothing will turn on our answer, I will assume for simplicity that we always appeal to the necessity of $A$. For ease of expression, however, I will sometimes use 'it is impossible that $\neg A$ ' and similar phrases to mean that it is necessary that $A$.

We need not take a proposition's having a necessitarian explanation to prevent it from also having some other form of explanation. To see this, consider, on the one

\footnotetext{
9 Kment (2014) develops an account of genuine (or in his terms, 'ontic') necessity that requires genuine forms of necessity to be stable in something very much like Lange's sense (p. 24; see also Kment 2015, p. 524). The doctrine of the open future poses a difficulty for Kment's account as well.
} 
hand, the proposition that there are no trisections of 23 objects and, on the other hand, the proposition that it is true that there are no trisections of 23 objects. If the former admits of necessitarian explanation, then surely the latter does as well. But one might think we can also explain the latter in a different way, since one might think that for any $A$ we can explain why it is true that $A$ by simply saying that $A$. We need not deny the existence of this other explanation.

Nor should we deny the possibility of elaborating or 'filling in' a necessitarian explanation to obtain a more detailed explanation. Thus we might fill in our explanation of why no one has ever divided 23 objects evenly into thirds by supplying more information about the impossibility of doing so. We might say, for instance, that any such division would involve placing the same natural number of objects into each of three partitions and that there is no natural number $n$ such that $3 n=23$. Nothing prevents us from giving this more detailed sort of explanation. I claim only that there is a sense in which we may explain why no one has ever divided 23 objects evenly into thirds simply by saying that it is impossible that anyone should have done so.

Nor, finally, should we deny the possibility of 'pruning' a necessitarian explanation to rid it of irrelevant aspects. Why has no one ever trisected 23 objects in Mexico City? We may give a necessitarian explanation by saying that it is impossible that anyone should have trisected 23 objects in Mexico City. But the mention of Mexico City seems irrelevant and so we may wish to give a pruned explanation simply by saying that it is impossible that anyone should have trisected 23 objects. I do not deny that this provides an explanation. I insist only that there is a sense in which an explanation is also provided by our first answer. It may be in some respect a worse explanation; it is an explanation nonetheless.

This, at any rate, is my position and I believe there is good reason to adopt it. However, it is possible to take a more deflationary view of the cases discussed above. Suppose we ask why it is the case that $A$, and suppose we answer by saying that it is necessary that $A$. One might take this not as an explanation of $A$ but rather as an indication that our question is somehow illegitimate or is otherwise appropriately left unanswered. A version of the account of genuineness that I will propose is available even to this sort of deflationist, provided she reinterprets my talk of necessitarian explanation as talk of the special way in which the necessity of a proposition can give us license to leave unanswered the question of why that proposition obtains. I, however, see no reason to doubt the legitimacy of such questions or the answers we are inclined to give and so I will discuss deflationism no further. ${ }^{10}$

I have discussed some particular cases of necessitarian explanation, but the phenomenon seems to be a general one. Indeed, one feels some sympathy for van Inwagen's (1996, p. 95) claim that

If showing that it is impossible for a certain state of affairs to obtain doesn't count as answering the question why that state of affairs does not obtain, I don't know what would count.

$\overline{10}$ I am grateful to an anonymous referee for calling my attention to the deflationary view. 
We may suspect, then, that any necessary proposition will admit of necessitarian explanation.

However, this general claim must be qualified. Consider the proposition that China is the most populous country. Since this proposition is known, it is epistemically necessary. Yet the proposition is in no way explained by its being necessary. After all, it is no part of why China is the most populous country that this is required by what is known. And so not every necessary proposition has a necessitarian explanation.

But some forms of necessity do seem to be such that every proposition that has that form of necessity does have a necessitarian explanation. Consider metaphysical necessity. All of the examples of necessitarian explanation given above are explanations of metaphysically necessary propositions, and indeed it seems that any metaphysically necessary proposition will admit of such explanation.

In fact, we can say something stronger. Given a metaphysically necessary proposition, we appear to be able to give what we might call a 'metaphysical-necessitarian' explanation of that proposition. For example, it is metaphysically necessary that no one has ever divided 23 objects evenly into thirds, and we may explain why no one has ever done this by saying that it is metaphysically impossible that anyone should have done so. Or again, we may explain why there are no gold atoms with one hundred protons by saying that it is metaphysically impossible that any gold atom should have one hundred protons. Again, we may explain why the property being a property is instantiated by saying that this is metaphysically necessary. It appears, then, that every metaphysically necessary proposition admits of such explanation.

We therefore distinguish the generic notion of necessitarian explanation from this more specific notion of metaphysical-necessitarian explanation. I will argue in $\S 3$ that metaphysical-necessitarian explanation is not the only specific notion of necessitarian explanation. But I must leave aside the interesting issue of the relationship between the generic and specific notions. Are the specific notions indeed properly understood as species of the generic notion? Or is the generic notion instead something like a disjunction of the specific notions? Or do they have some other relationship? Such questions will have to await another time.

Let us say that a form of necessity $\Phi$ is explanatory just in case every $\Phi$-necessary proposition has a $\Phi$-necessitarian explanation. Metaphysical necessity is then an explanatory form of necessity. Epistemic necessity, by contrast, is a nonexplanatory form of necessity, since the proposition that China is the most populous country, at least, cannot be explained by saying that it is epistemically necessary. (I leave aside the question whether some epistemically necessary propositions can be explained in this way.)

One naturally seeks to understand metaphysical-necessitarian explanation in terms of some more familiar form of explanation. And in the contemporary metaphysical context a salient thought is likely to be that it is a form of grounding explanation. In a grounding explanation, we explain something by saying what grounds it. ${ }^{11}$ Thus we may give a grounding explanation of the proposition that Europe was at war in 1940 by citing the various military actions its citizens were engaged in. Or again, we may give a

11 For discussion of ground see Fine (2001), Schaffer (2009) and Rosen (2010), among others. I take no position on what Raven (2015) calls the unionist/separatist debate. 
grounding explanation of the proposition that a given barn is red by appeal to its being crimson. Again, we may give a grounding explanation of a disjunctive proposition by appeal to one of its true disjuncts. One might propose that a metaphysical-necessitarian explanation is just a grounding explanation of a certain sort, one whose explanandum is of the form ' $A$ ' and whose explanans is of the form 'it is metaphysically necessary that $A$ '.

I would like to suggest that we have reason to reject this grounding proposal. (I will present only a brief defense of this suggestion here as I develop a very similar argument at greater length in Glazier (2017)). In the first place, there seems no real reason to accept the proposal. It is hardly clear, for instance, that the proposition that there are no trisections of 23 objects is grounded in the proposition that it is metaphysically necessary that there are no such trisections, although this is what the proposal requires.

There are also considerations which tell positively against the proposal. One such consideration is that the proposal is inconsistent with a natural condition on the grounds of disjunctive propositions. To see this, consider a disjunctive proposition $A \vee B$. What are the conditions under which an arbitrary proposition will ground this disjunction? Of course it is generally agreed that a disjunctive proposition like $A \vee B$ is grounded in its true disjuncts, but this does not mean that the proposition cannot also be grounded in some other way. Indeed, since ground is transitive ${ }^{12}$ the grounds of the true disjuncts will also ground the disjunction and yet these grounds may not themselves be true disjuncts of $A \vee B$. What then can be said in general about when a proposition will ground $A \vee B$ ?

Although $A \vee B$ can be grounded in propositions other than its true disjuncts, one still has the sense that these grounds, whatever they are, must be somehow connected to the true disjuncts. A natural thought is that the grounding of the disjunction should 'proceed by way of' or be 'mediated through' its true disjuncts. In Fine's (2012, p. 63) phrase, the true disjuncts are the conduit through which truth to the disjunction should flow. We may capture this thought by saying that an arbitrary proposition can ground a disjunction only if either it is itself a true disjunct $o r$ it grounds a true disjunct. ${ }^{13}$

The proposal that metaphysical-necessitarian explanation is a form of grounding explanation is inconsistent with this condition on the grounds of disjunctive propositions. To see this, let $p$ be the proposition that it is raining. However fickle the weather, it is always the case that either $p$ is true or $p$ is false. Why? Why is it that either $p$ is true or $p$ is false? Because it is metaphysically impossible for it to fail to be one of the two. That $p$ is true or false, then, admits of metaphysical-necessitarian explanation. If the grounding proposal is correct, the proposition that $p$ is true or false must therefore be grounded in the proposition that it is metaphysically necessary that $p$ is true or false.

Yet the proposition that it is metaphysically necessary that $p$ is true or false is not a true disjunct of the proposition that $p$ is true or false. And nor does it ground a true disjunct. After all, whichever disjunct is the true one-whether $p$ is true or

\footnotetext{
12 Pace Schaffer (2012).

13 Fine (2012) argues that this condition is too strong. His logic of ground contains a disjunction elimination rule that supports only a weaker condition on the grounds of disjunctions. Our argument can be modified to accommodate Fine's view.
} 
$p$ is false-that disjunct is metaphysically contingent. But since propositions metaphysically necessitate what they ground, ${ }^{14}$ no metaphysically necessary proposition can ground anything metaphysically contingent. And since metaphysical necessity is standardly assumed to obey the 4 axiom $(\square A \rightarrow \square \square A$ ), the proposition that it is metaphysically necessary that $p$ is true or false will itself be metaphysically necessary. The proposition that it is metaphysically necessary that $p$ is true or false, then, cannot ground a true disjunct of the proposition that $p$ is true or false. And so the grounding proposal is inconsistent with our natural condition on the grounds of disjunctive propositions.

Moreover, it appears that one might coherently admit a host of metaphysicalnecessitarian explanations while denying even the intelligibility of ground and grounding explanation. Grounding explanation, after all, may be thought of as explanation from 'below': we explain one thing by appeal to another, more metaphysically basic thing. And one might deny the intelligibility of such explanation out of a conviction that there is simply no sense to be made of such metaphysical belowness or basicness or priority or fundamentality. But metaphysical-necessitarian explanation does not seem to presuppose any such 'hierarchical' notion. One need not think of the world as hierarchical, for example, in order to agree that there are no trisections of 23 objects because there cannot be. Thus even one who was utterly skeptical of ground in this way might be willing to countenance metaphysical-necessitarian explanation. But if the grounding proposal were correct such a position would be incoherent.

For these reasons, this proposal should be rejected. We cannot understand metaphysical-necessitarian explanation in terms of the familiar notion of grounding explanation in this way. I must leave for another time the interesting question whether it can be understood in terms of some less familiar form of explanation, such as essentialist explanation (Glazier 2017).

In the remainder of this section I would like to address a potential objection to my claim that metaphysical necessity is an explanatory form of necessity. The objection is that the claim leads to circular explanation. To see why one might think this, let it be metaphysically necessary that $A$ (in symbols: $\square A$ ). Given the 4 axiom, if metaphysical necessity is explanatory then $\square A$ will admit of explanation in terms of $\square \square A$. But one might take the view that an iterated modal proposition will always admit of explanation in terms of a noniterated modal proposition, and in particular that $\square \square A$ will admit of explanation in terms of $\square A$. We therefore appear to have one proposition $(\square A)$ explaining another proposition $(\square \square A)$ which itself explains the first.

Of course, it is hardly clear that the objector is correct to take $\square \square A$ to be explained by $\square A$. But even if she is, there seems no reason to think the pattern of explanation here would be objectionably circular. After all, such patterns can appear elsewhere without issue. Consider propositions about what is intrinsically good for someone or what makes someone's life go well. Suppose, for instance, that wisdom is better for Smith than wealth. Let us suppose that a preference satisfaction account of well-being is correct, so that this proposition admits of grounding explanation in terms of the proposition that Smith prefers wisdom to wealth. But suppose further that when we

14 Pace Leuenberger (2014) and Skiles (2015). 
ask Smith why she prefers wisdom to wealth, she answers that wisdom is better for her than wealth. Whatever objections this answer may face, it is Smith's reason for her preference. There is thus a familiar sense in which we may explain why Smith prefers wisdom to wealth by citing her reason: wisdom is better for her than wealth. Here we have one proposition explaining another proposition, which itself explains the first, and yet there is nothing objectionably circular about this pattern of explanation.

The objector may insist that her case is different, since there the two explanations are of the same kind. But there is little reason to accept this response. For what would this kind be? Certainly not necessitarian explanation. After all, though the explanation of $\square A$ in terms of $\square \square A$ is necessitarian, the explanation of $\square \square A$ in terms of $\square A$ cannot be, since it is not of the right form. Indeed, if the latter is an explanation at all it is presumably a grounding explanation. But the former, I have argued, is not a grounding explanation. And I do not know how the two explanations might otherwise be seen to be members of a single kind.

In any event, for our purposes little is lost if we adopt a weaker conception of what is required for a form of necessity $\Phi$ to be explanatory. Rather than require every $\Phi$ necessary proposition to have a $\Phi$-necessitarian explanation in order for $\Phi$-necessity to be explanatory, we might require only that every nonmodal $\Phi$-necessary proposition has such an explanation. Clearly, the claim that metaphysical necessity is explanatory in this weaker sense is not subject to the objection. My own view, however, is that there is good reason to maintain that it is explanatory even in the stronger sense.

\section{Genuine necessity as explanatory necessity}

For a form of necessity to be genuine, I propose, is just for it to be explanatory. Thus when a proposition has a genuine form of necessity $\Phi$, that provides a $\Phi$ necessitarian explanation of why the proposition obtains. In this sense, the genuine forms of necessity are those that are explanatorily sufficient for truth. They alone, we might say, impose constraints on the world that require certain propositions to be true. ${ }^{15}$ Kment is therefore correct that a particularly formidable obstacle prevents a genuinely impossible proposition $p$ from being true. The obstacle is simply this: the genuine necessity of $\neg p$ constrains the world to be such that $p$ is false.

I argued in $\S 3$ that metaphysical necessity is explanatory while epistemic necessity is not. The explanatory account therefore correctly classifies the former as genuine and the latter as nongenuine. ${ }^{16}$ Of course, if the account is to be adequate it must correctly classify not just these two forms of necessity but all such forms. I cannot here undertake an exhaustive survey but I will briefly consider three further forms.

Deontic necessity, in the sense of what is morally required, is not a genuine form of necessity. And nor is it explanatory. After all, deontic necessity is not even logically

\footnotetext{
15 Related notions of explanatory constraint have recently been discussed by Lange (2016) and (in unpublished work) by Michael Bertrand.

16 The explanatory account also correctly classifies as nongenuine the epistemic conception of analytic necessity mentioned in n. 5. It is no part of why bachelors are unmarried, after all, that some epistemic condition holds. This form of necessity (if indeed it is a form of necessity) is nonexplanatory and thus nongenuine.
} 
sufficient for truth. For it is, we may suppose, deontically necessary that there is no torture in the world, and yet there is torture. This form of necessity is a fortiori not explanatorily sufficient for truth either: some deontically necessary propositions are false and so cannot be explained by saying that they are deontically necessary.

What of natural necessity, the necessity attaching to what is required by the laws of nature? This is the sense in which, for example, the energy of an isolated system must remain constant. Like metaphysical necessity, and unlike epistemic and deontic necessity, this form of necessity seems genuine. In Kmentian terms, there seems to be some obstacle that prevents the energy of an isolated system from increasing or decreasing. And natural necessity also seems explanatory. Why, for example, has no one ever built a perpetual motion machine? Because it is naturally impossible that anyone should have done so. Or again, as van Fraassen (1989, p. 28; quoted in Schaffer 2016) observes, 'Wood burns when heated, because wood must burn when heated.'

But is it really the case that every naturally necessary proposition admits of naturalnecessitarian explanation? ${ }^{17}$ What about a naturally necessary proposition that is also metaphysically necessary, such as that there are no trisections of 23 objects? One might object that we cannot explain why there are no such trisections by saying that they are naturally (as opposed to metaphysically) impossible.

But how can this objection be sustained? Consider any $X \mathrm{~s}$ whatsoever that are naturally impossible. To say that $X$ s are naturally impossible is to say that nature itself (or its laws) forbids the existence of $X \mathrm{~s}$. And why would it not be a perfectly good explanation of why there are no $X$ s to say that nature itself forbids them?

The only answer the objector can give, it seems to me, is that nature does not, properly speaking, forbid trisections of 23 objects. What nature forbids, she might say, are things like the construction of a perpetual motion machine, or wood that fails to burn when heated. And in support of this claim she might say that the prohibition on such things has its source, in a certain sense, in the natural order. The prohibition on trisecting 23 objects, by contrast, has its source not in nature but in mathematics.

Although the objector's answer is vague, its vagueness does not matter. For once this answer is given it is clear how the objection may be met. The objector admits a distinction between those propositions that have their source in the natural order and those that do not. In the former category we find the proposition that there are no perpetual motion machines; in the latter, that there are no trisections of 23 objects. From the objector's perspective, I think, propositions in the latter category are not properly taken to be naturally necessary. She should therefore restrict the domain of natural necessity to those propositions that have their source in the natural order. ${ }^{18}$ But once the objector understands natural necessity in this restricted way her objection vanishes. For on her view it will be only metaphysically necessary, not naturally necessary, that there are no trisections of 23 objects. And so by her own lights there will be no bar to taking natural necessity to be explanatory.

\footnotetext{
17 I am grateful to Jennifer Wang for discussion on this point.

18 Cf. Fine (2002, p. 279): 'I conclude that there are three distinct sources of necessity-the identity of things, the natural order, and the normative order-and that each gives rise to its own peculiar form of necessity.'
} 
As in the case of metaphysical-necessitarian explanation, many will seek to understand natural-necessitarian explanation in terms of some more familiar explanatory notion. In the metaphysical case, the salient notion is grounding explanation. In the natural case, it is causal explanation. But just as we cannot understand metaphysical-necessitarian explanation as a form of grounding explanation, neither can we understand natural-necessitarian explanation as a form of causal explanation, at least if causal explanation is understood to require that the explanans cause the explanandum. ${ }^{19}$ For it might be thought that there are uncaused propositions which nevertheless have natural-necessitarian explanations. Suppose, for instance, that it is naturally necessary that all electrons have spin $1 / 2$. It will then be a naturally necessary proposition that at the moment of the Big Bang all electrons had spin 1/2, and so this proposition will admit of natural-necessitarian explanation. Yet the proposition might also be thought to be uncaused, on the grounds that there is no preceding event that could have caused it (or the event to which it corresponds).

The claim that this proposition is uncaused might be challenged. But we need not insist on the truth of this claim. We need only insist that any reasonable account of natural-necessitarian explanation should at least be consistent with it. After all, it is a substantive cosmological question whether any event preceded our proposition, and it is a substantive metaphysical question whether a proposition can have a cause even if no event precedes it. ${ }^{20}$ It is thus a substantive question whether our proposition is uncaused, and so the claim that it is should not be ruled out merely by our account of what natural-necessitarian explanation is. We therefore should not understand such explanation as a form of a causal explanation.

Let us finally, and very briefly, consider historical necessity. This form of necessity is less well understood than the previous forms - among other things, it is controversial whether it is genuine-and so it is hard to show definitively that it does not pose a difficulty for the explanatory account. But I think a plausible case can be made that it does not. On the one hand, if one takes historical necessity to be nongenuine, then it will be natural to understand the claim that a given proposition $p$ is historically necessary as nothing more than the claim that $p$ follows, in a certain sense, from the true propositions about the past and present. And historical necessity so understood does not seem explanatory. For suppose $p$ is a true proposition about the past. Then $p$ 's historical necessity will amount to no more than its following from the truths about the past and present, one of which is $p$ itself. And how could this explain why $p$ is true? If, on the other hand, historical necessity is genuine, then to say that a proposition is historically necessary is to say that there is no genuinely possible way for events to unfold such that it fails to obtain. Understood this way, historical necessity seems explanatory. Imagine, for instance, that Booth comes to regret killing Lincoln. Racked with guilt, he would give anything to undo his crime. Yet try as he might he is (still) Lincoln's assassin. Why? Because there is no way events can unfold such that he fails to be Lincoln's assassin. His being Lincoln's assassin, that is, is 'fixed'. And in

\footnotetext{
19 I will not here address the proposal that natural-necessitarian explanation is a form of causal explanation understood in some other way, as, for instance, in Skow (2014).

20 Cf. Bernstein (2016, p. 24): 'It is a substantive metaphysical question whether causes always precede their effects.'
} 
general, if historical necessity is genuine then it seems that any historically necessary proposition will admit of such historical-necessitarian explanation. The explanatory account appears defensible, then, whether or not this form of necessity is genuine.

But even if the account's classifications are allowed to stand-even if we take the account to be extensionally adequate - there remains the question of whether it is correct as an account of what genuineness is. And one might here object that the account makes genuineness depend implausibly on our practices. How could the genuineness of a form of necessity consist in our being willing to give certain explanations? Surely the reverse is much more plausible: it is because metaphysical necessity is genuine, for instance, that we are willing to explain why there are no trisections of 23 objects by saying that such trisections are metaphysically impossible.

But the explanatory account, properly understood, need not render genuineness dependent on our practices. For we may appeal to the familiar distinction between the 'ontological' and 'communicative' senses of explanation (Strevens 2008, pp. 67). In the ontological sense, an explanation is a set of facts about the world. In the communicative sense, by contrast, an explanation is a certain kind of communicative act: an attempt to convey some of these explanatory facts. We should agree that it is because metaphysical necessity is genuine that certain communicative explanations are apt. But it is quite consonant with this to take its genuineness to consist in its figuring in certain ontological explanations. And the latter need not be taken to involve our practices in any way.

But is there not some deeper feature of the genuine forms of necessity, apart from anything having to do with explanation, that is responsible for their figuring in these explanations in the first place? And is this deeper feature not what genuineness itself properly consists in? The first question, important though it is, I must leave for another time. If the view defended above is right, however, the answer to the second is 'no' regardless. To be genuine, I have argued, is nothing more than to impose constraints on the world which have real explanatory power-that is, to provide necessitarian explanation.

Acknowledgements My thanks to Selim Berker, Harjit Bhogal, Dave Chalmers, Cian Dorr, Kit Fine, Matthew Hanser, Marc Lange, Kris McDaniel, Carla Merino-Rajme, Jessica Moss, Asya Passinsky, Zee Perry, Gideon Rosen, Erick Sam, Erica Shumener, Ted Sider, Sharon Street, Michael Strevens, Jennifer Wang and to audiences at NYU, Iowa State University, Koç University, Ashoka University and the APA Pacific Division Meeting.

Funding I am grateful for the support of the John Templeton Foundation and of the Program of Postdoctoral Fellowships at the Universidad Nacional Autónoma de México.

\section{References}

Barnes, E., \& Cameron, R. P. (2011). Back to the open future. Philosophical Perspectives, 25(1), 1-25. Bernstein, S. (2016). Grounding is not causation. Philosophical Perspectives, 30(1), 21-38.

Boghossian, P. (1996). Analyticity reconsidered. Nô̂s, 30(3), 360-91.

Chalmers, D. J. (2011). The nature of epistemic space. In A. Egan \& B. Weatherson (Eds.), Epistemic modality (pp. 60-107). Oxford: Oxford University Press.

DeRose, K. (1991). Epistemic possibilities. Philosophical Review, 100(4), 581-605.

Edgington, D. (2004). Two kinds of possibility. Aristotelian Society Supplementary, 78(1), 1-22.

Egan, A., \& Weatherson, B. (Eds.). (2011). Epistemic modality. Oxford: Oxford University Press. 
Fine, K. (2001). The question of realism. Philosophers' Imprint, 1(1), 1-30.

Fine, K. (2002). The varieties of necessity. In T. S. Gendler \& J. Hawthorne (Eds.), Conceivability and possibility (pp. 253-81). Oxford: Oxford University Press.

Fine, K. (2012). Guide to ground. In F. Correia \& B. Schnieder (Eds.), Metaphysical grounding: Understanding the structure of reality (pp. 37-80). Cambridge: Cambridge University Press.

Glazier, M. (2017). Essentialist explanation. Philosophical Studies, 174, 2871-2889.

Hacking, I. (1967). Possibility. Philosophical Review, 76(2), 143-68.

Jenkins, C. S. (2011). Explanation and fundamentality. In B. Schnieder, A. Steinberg, \& M. Hoeltje (Eds.), Ontological dependence, supervenience, and response-dependence (pp. 211-242). Munich: Philosophia Verlag.

Kment, B. (2006). Counterfactuals and the analysis of necessity. Philosophical Perspectives, 20(1), 237302 .

Kment, B. (2014). Modality and explanatory reasoning. Oxford: Oxford University Press.

Kment, B. (2015). Replies to Sullivan and Lange. Philosophy and Phenomenological Research, 91(2), 516-39.

Kripke, S. A. (1980). Naming and necessity. Cambridge: Harvard University Press.

Lange, M. (2009). Laws and lawmakers: Science, metaphysics, and the laws of nature. Oxford: Oxford University Press.

Lange, M. (2016). Because without cause: Non-causal explanations in science and mathematics. Oxford: Oxford University Press.

Leuenberger, S. (2014). Grounding and necessity. Inquiry, 57(2), 151-74.

Lewis, D. (1986). On the plurality of worlds. Oxford: Blackwell.

Murray, A., \& Wilson, J. (2012). Relativized metaphysical modality. In D. Zimmerman \& K. Bennett (Eds.), Oxford studies in metaphysics (Vol. 7, pp. 189-226). Oxford: Oxford University Press.

Quine, W. V. (1943). Notes on existence and necessity. Journal of Philosophy, 40(5), 113-27.

Raven, M. J. (2015). Ground. Philosophy Compass, 10(5), 322-33.

Raven, M. J. (2016). Fundamentality without foundations. Philosophy and Phenomenological Research, 93(3), 607-626.

Rosen, G. (2006). The limits of contingency. In F. MacBride (Ed.), Identity and modality (pp. 13-39). Oxford: Oxford University Press.

Rosen, G. (2010). Metaphysical dependence: Grounding and reduction. In B. Hale \& A. Hoffmann (Eds.), Modality: Metaphysics, logic, and epistemology (pp. 109-35). Oxford: Oxford University Press.

Schaffer, J. (2009). On what grounds what. In D. J. Chalmers, D. Manley, \& R. Wasserman (Eds.), Metametaphysics: New essays on the foundations of ontology (pp. 347-83). Oxford: Oxford University Press.

Schaffer, J. (2012). Grounding, transitivity, and contrastivity. In F. Correia \& B. Schnieder (Eds.), Metaphysical grounding: Understanding the structure of reality (pp. 122-38). Cambridge: Cambridge University Press.

Schaffer, J. (2016). Grounding in the image of causation. Philosophical Studies, 173, 49-100.

Sider, T. (2001). Four-dimensionalism: An ontology of persistence and time. Oxford: Oxford University Press.

Sider, T. (2003). Reductive theories of modality. In M. J. Loux \& D. W. Zimmerman (Eds.), The Oxford handbook of metaphysics (pp. 180-208). Oxford: Oxford University Press.

Sider, T. (2011). Writing the book of the world. Oxford: Oxford University Press.

Skiles, A. (2015). Against grounding necessitarianism. Erkenntnis, 80, 717-51.

Skow, B. (2014). Are there non-causal explanations (of particular events)? British Journal for the Philosophy of Science, 65, 445-67.

Soames, S. (2011). Kripke on epistemic and metaphysical possibility: Two routes to the necessary a posteriori. In A. Berger (Ed.), Saul Kripke (pp. 167-88). Cambridge: Cambridge University Press.

Strevens, M. (2008). Depth: An account of scientific explanation. Cambridge: Harvard University Press.

Teller, P. (1972). Epistemic possibility. Philosophia, 2(4), 303-20.

Van Fraassen, B. C. (1989). Laws and symmetry. Oxford: Oxford University Press.

Van Inwagen, P. (1996). Why is there anything at all? Proceedings of the Aristotelian Society, Supplementary Volumes, 70, 95-120.

Williamson, T. (2016). Modal science. Canadian Journal of Philosophy, 46(4-5), 453-92.

Wilson, A. (2013). Schaffer on laws of nature. Philosophical Studies, 164, 653-67.

Wilson, J. (2014). No work for a theory of grounding. Inquiry, 57(5-6), 535-579. 